\title{
Grand challenges in child and neurodevelopmental psychiatry
}

\section{E. Jane Costello*}

Center for Developmental Epidemiology, Duke University Medical School, Durham, NC, USA

*Correspondence: elizabeth.costello@duke.edu

Humans have known for at least 3500 years that the functioning of the brain affects behavior, and that damage to the brain causes behavioral malfunctions (Breasted, 1930). Around 2400 years ago, Hippocrates taught that "from the brain, and from the brain only, arise our pleasures, joy, laughter and jests, as well as our sorrows, pains, griefs, and tears." He was also aware that "...all the most acute, most powerful, and most deadly diseases, and those which are most difficult to be understood by the inexperienced, fall upon the brain" (Adams, 1939, p.360).

Those who contribute to modern understanding of neurodevelopmental psychiatry are not "the inexperienced", but experts in a wide range of disciplines and areas of knowledge - as, indeed, they need to be. As Steven Rose put it, "Perhaps in a sense it (the brain) is the greatest challenge for science as a whole, beyond moon landings, the ultimate particles of the physicist and the depths of astronomical space" (Rose, 1973). Or as James Watson joked: "The brain boggles the mind" (Watson, 1992).

In confronting this challenge, we have several resources. First, more than a 100 years of painstaking study of "normal" development, set on a firm scientific footing by William Preyer (1841-1897) and others, has led to the current explosion of work exploiting methods such as neuroimaging to map changes in mental, behavioral, and emotional capacities onto changes in the brain. This work has given us not only invaluable knowledge about psychological development, but also a sense of what is "normal" at different developmental stages in different areas of functioning, such as intelligence, self-regulation, and social functioning. This body of knowledge can help us to evaluate the functioning of children who come to the clinic in need of help.

Second, psychiatry is beginning, at last, to take seriously the developmental nature of psychopathology. A recent national epidemiological study of adults In the United States reported that "Half of all lifetimecases start by age 14 years and three fourths by age 24 years". (Kessler et al., 2005) This is a misestimate, caused by relying on retrospective recall by adults of their lifetime history of mental illness. Prospective studies beginning in childhood set the onset of most psychiatric disorders (apart from the dementias) in the first two decades of life (Jaffee et al., 2005).

The first grand challenge is thus to link what we learn about the developing brain to the earliest appearance of symptoms psychiatric disorder. In his book "The Development of Psychopathology: Nature and Nurture" (Pennington, 2002), Bruce Pennington posed the question "Why do we need a developmental understanding of psychopathology?", and gave four answers that provide a template for our program of work for this journal.

\section{ETIOLOGY}

We need work on how the relative timing of gene expression and environmental risk influences behavioral outcomes. Pennington cites the famous work of Hubel and Wiesel on the development of cats' visual cortex, showing that "neural connections present early in life can be modified by visual experience".(Wiesel, 1982) A recent study of children adopted from Romanian orphanages, showing that recovery of intellectual abilities depends on age at adoption (Rutter, 1998) is another example.

\section{NEUROBIOLOGY}

We need work on how genes and environment interact developmentally to affect outcomes. How does maternal smoking during pregnancy affect the fetus? How does the increase in testosterone that precedes menarche increase the risk of depression in girls? The rapidly-increasing number of multi-disciplinary research teams will be needed to answer these questions.

\section{NEUROPSYCHOLOGY}

Localization of brain functions varies with development. Tracking when and how different brain functions are mediated by different brain structures is a huge research challenge.

\section{SYMPTOMS}

Work on how developmental stage affects the manifestation of different types of psychopathology is still rudimentary. What happens to ADHD when children grow out of jumping on the furniture? How do such phenomenological changes manifest themselves at the level of brain structure and functioning, not to mention gene expression?

We need articles not only in each of these areas, but articles that combine several of these types of developmental understanding.

The second challenge is to learn how to intervene to prevent the development of early symptoms into full-blown disorders, with the attendant risk of recurrence and impaired functioning. Prevention and development are intimately intertwined: only when we understand the developmental course of a symptom or disorder can we have a solid scientific underpinning for prevention. On the other hand, a well-designed prevention trial will implicitly or explicitly test a developmental theory of disease. I hope that such prevention trials will find their way into this journal.

The third challenge is to make our treatments more developmentally sensitive. Why are the effects of SSRIs different at different ages? How early can CBT be effective?

Child psychiatric research has the enormous advantage of access to a century of careful normative study of child development, as well as to a more recent explosion of developmental brain research. The grand challenge is to bring all this richness together and to use it to raise healthy children.

The goal of Child and Neurodevelopmental Psychiatry is to be a home for research that will meet these challenges. We have an amazing group of Editors, experts across the range of disciplines. Several come from countries outside the range of usual suspects, with the goal of making this a truly open-access journal for the whole world of research. I look forward to working with you all. 


\section{REFERENCES}

Adams, F. (1939). The Genuine works of Hippocrates. Baltimore: Williams and Wilkins.

Breasted, J. (1930). The Edwin Smith Surgical Papyrus. Chicago, IL: University of Chicago Press.

Jaffee, S., Harrington, H., Cohen, P., and Moffitt, T. E. (2005). Cumulative prevalence of psychiatric disorder in youth. J. Am. Acad. Child Adolesc. Psychiatry 44, 406-407.

Kessler, R. C., Berglund, P., Demler, O., Jin, R., and Walters, E. E. (2005). Lifetime prevalence and Age-of-onset distributions of DSM-IV disorders in the National Comorbidity survey replication. Arch. Gen. Psychiatry 62, 593-602.
Pennington, B. F. (2002). The Development of Psychopathology: Nature and Nurture. New York: Guilford Press.

Rose, S. (1973). The Conscious Brain. London: Vintage Books.

Rutter, M. (1998). Developmental catch-up, and deficit, following adoption after severe global early privation. English and Romanian Adoptees (ERA) Study Team. J. Child Psychol. Psychiatry 39, 465-476.

Watson, J. D. (1992). Discovering the Brain. Washington DC: National Academy Press.

Wiesel, T. N. (1982). The postnatal development of the visual cortex and the influence of environment. Biosci. Rep. 2, 351-377.
Received: 04 May 2010; accepted: 04 May 2010; published online: 08 July 2010.

Citation: Costello EJ (2010) Grand challenges in child and neurodevelopmental psychiatry. Front. Psychiatry 1:14. doi: 10.3389/fpsyt.2010.00014

This article was submitted to Frontiers in Child and Neurodevelopmental Psychiatry, a specialty of Frontiers in Psychiatry.

Copyright (c) 2010 Costello. This is an open-access article subject to an exclusive license agreement between the authors and the Frontiers Research Foundation, which permits unrestricted use, distribution, and reproduction in any medium, provided the original authors and source are credited. 